Fixed Point Theory, 22(2021), No. 1, 93-104

DOI: $10.24193 /$ fpt-ro.2021.1.07

http://www.math.ubbcluj.ro/ nodeacj/sfptcj.html

\title{
AN INERTIAL CENSOR-SEGAL ALGORITHM FOR SPLIT COMMON FIXED-POINT PROBLEMS
}

\author{
HUANHUAN CUI*, HAIXIA ZHANG** AND LUCHUAN CENG*** \\ *Department of Mathematics, Luoyoang Normal University, Luoyang 471934, China \\ E-mail: hhcui@live.cn \\ ** Department of Mathematics, Henan Normal University, Xinxiang 453007, China \\ E-mail: zhx6132004@sina.com \\ (Corresponding author) \\ ***Department of Mathematics, Shanghai Normal University, Shanghai 200234, China \\ E-mail: zenglc@hotmail.com
}

\begin{abstract}
In this paper we study the split common fixed-point problem in Hilbert spaces. To speed up its convergence, we modify the algorithm recently introduced by Censor and Segal. Moreover, the step-size in our algorithm is independent of the norm of the given linear mapping. Under some mild conditions, we establish two weak convergence theorems of the proposed algorithm.

Key Words and Phrases: Split common fixed-point problem, firmly quasi-nonexpansive mappings, inertial Censor-Segal algorithm.
\end{abstract}

2020 Mathematics Subject Classification: 47J25, 47J20, 49N45, 65J15, 47H10.

\section{REFERENCES}

[1] F. Alvarez, H. Attouch, An inertial proximal method for maximal monotone operators via discretization of a nonlinear oscillator with damping, Set-Valued Anal., 9(2001), 3-11.

[2] H.H. Bauschke, P.L. Combettes, Convex Analysis and Monotone Operator Theory in Hilbert Spaces, Springer Verlag, 2011.

[3] O.A. Boikanyo, A strongly convergent algorithm for the split common fixed point problem, Appl. Math. Comput., 265(2015), 844-853.

[4] R.I. Bot, E.R. Csetnek, An inertial forward-backward-forward primal-dual splitting algorithm for solving monotone inclusion problems, Numerical Algorithms, 71(2016), 519-540.

[5] R.I. Bot, E.R. Csetnek, C. Hendrich, Inertial Douglas-Rachford splitting for monotone inclusion, Appl. Math. Comput., 256(2015), 472-487.

[6] C. Byrne, Iterative oblique projection onto convex sets and the split feasibility problem, Inverse Problems, 18(2002), 441-453.

[7] C. Byrne, A unified treatment of some iterative algorithms in signal processing and image reconstruction, Inverse Problems, 20(2004), 103-120.

[8] A. Cegielski, General method for solving the split common fixed point problem, J. Optim. Theory Appl., 165(2015), 385-404.

[9] Y. Censor, T. Elfving, A multiprojection algorithms using Bregman projection in a product space, Numerical Algorithms, 8(1994), 221-239.

This work was supported by the Natural Science Foundation of China (No. 11701154) and Key Scientific Research Projects of Universities in Henan Province (No. 19B110010). 
[10] Y. Censor, A. Segal, The split common fixed point problem for directed operators, J. Convex Anal., 16(2009), 587-600.

[11] H. Cui, F. Wang, Iterative methods for the split common fixed point problem in Hilbert spaces, Fixed Point Theory Appl., 2014(2014), 1-8.

[12] Y. Dang, J. Sun, H. Xu, Inertial accelerated algorithms for solving a split feasibility problem, J. Indus. Manage. Optim., 13(2017), 1383-1394.

[13] P. Kraikaew, S. Saejung, On split common fixed point problems, J. Math. Anal. Appl., 415(2014), 513-524.

[14] G. López, V. Martin-Márquez, F. Wang, H.-K. Xu, Solving the split feasibility problem without prior knowledge of matrix norms, Inverse Problems, 28(2012), 085004.

[15] A. Moudafi, A note on the split common fixed-point problem for quasi-nonexpansive operators, Nonlinear Anal., 74(2011), 4083-4087.

[16] A. Moudafi, The split common fixed point problem for demicontractive mappings, Inverse Problems, 26(2010), 055007.

[17] R. Tibshirani, Regression shrinkage and selection via the lasso, J. Royal Statistical Society, Series B, 58(1996), 267-88.

[18] F. Wang, A new method for split common fixed-point problem without priori knowledge of operator norms, J. Fixed Point Theory Appl., 19(2017), 2427-2436.

[19] H.-K. Xu, A variable Krasnosel'skii-Mann algorithm and the multiple-set split feasibility problem, Inverse Problems, 22(2006), 2021-2034.

[20] H.-K. Xu, Iterative methods for the split feasibility problem in infinite-dimensional Hilbert spaces, Inverse Problems, 26(2010), 105018.

[21] H.-K. Xu, Properties and iterative methods for the Lasso and its variants, Chin. Ann. Math. Ser. B, 35(2014), 501-518.

[22] H. Zou, T. Hastie, Regularization and variable selection via the elastic net, Journal of the Royal Statistical Society, 67(2005), 301-320.

Received: February 14, 2019; Accepted: September 12, 2020. 
